\title{
Reinstating reptiles: from clueless creatures to esteemed models of cognitive biology
}

\author{
Gilles De Meester* and Simon Baeckens \\ Functional Morphology Lab, Biology Department, University of Antwerp, Belgium \\ *Corresponding author's e-mail address: gilles.demeester@uantwerp.be
}

Published online: 16 September 2021

\begin{abstract}
Non-avian reptiles have long been neglect in cognitive science due to their reputation as slow and inflexible learners, but fortunately, this archaic view on reptile cognition is changing rapidly. The last two decades have witnessed a renewed interest in the cognitive capacities of reptiles, and more ecologically relevant protocols have been designed to measure such abilities. Now, we appreciate that reptiles possess an impressive set of cognitive skills, including problem-solving abilities, fast and flexible learning, quantity discrimination, and even social learning. This special issue highlights current research on reptiles in cognitive biology and showcases the diversity of research questions that can be answered by using reptiles as study model. Here, we briefly address (the key results of) the contributing articles and their role in the endeavour for total inclusion of reptiles in cognitive biological research, which is instrumental for our understanding of the evolution of animal cognition. We also discuss and illustrate the promising potential of reptiles as model organisms in various areas of cognitive research.
\end{abstract}

\section{Keywords}

animal cognition, behavioural research, non-avian reptiles, learning.

\section{A brief history}

Non-avian reptiles (turtles, squamates, tuatara, and crocodiles) have long suffered from a reputation of being slow and adamant creatures incapable of learning. Even in scientific writings as late as the 1970s reptiles were described as 'reflex machines' (Jerison, 1973) and 'intellectual dwarfs' (Turner, 1892), or as having 'a very small brain which does not function vigorously' (Robin, 1973). This poor reputation was mainly based on sparse 
anecdotical evidence, and on the relative small size and simplicity of their brains compared to endotherms (Burghardt, 1977).

A sad consequence was that throughout much of the last century, reptiles were side-lined in the emerging field of animal cognition. The few studies published during that period initially seemed to confirm the, at that time popular, notion of the cognitive inferiority of reptiles by, for instance, reporting that lizards failed to learn a simple detour task (moving over a small transparent petri dish to obtain a prey inside) even after being tested thrice per week for three months (Cookson, 1962). Many of these earlier studies were later criticized by Burghardt (1977) in the first exhaustive review on reptile learning. Gordon M. Burghardt claimed that the underperformance of reptiles was partially due to inadequate and ecological irrelevant experimental study designs, such as suboptimal room temperatures or inefficient reinforcers. Motivation in particular seemed to be a major problem in reptilian learning studies. Food, for instance, which is commonly used as a motivator for rodents and birds to participate in cognitive tasks, is according to Burghardt (1977) far less appealing to reptiles, given their low metabolic rate and irregular feeding habits (e.g., snakes can consume large prey followed by months of inactivity).

Despite that Burghardt (1977) provided useful recommendations to improve studies of reptilian cognition, the taxon was largely ignored in cognitive research for the next decades (Szabo et al., 2021b). Only very recently, the field of animal cognition experienced a true 'reptilian renaissance', in which the myth of the blunt, slow reptilian has finally been rebuked. An increasing number of studies are now investigating cognition in reptiles or use reptiles as study animals to answer broader questions about the evolution of cognition. Valuable new insights are gained by employing more adequate cognitive protocols (see e.g., Whiting \& Noble, 2018 for practical guidelines and Figures 1 and 2 for examples). For starters, cognition is now more often studied in a (semi-)natural setting, using outdoor enclosures (Noble et al., 2012) or camera-trapping (Pettit et al., 2021) and radio-tracking in the wild (Roth \& Krochmal, 2015, 2018). Research has also progressed by adopting protocols in which reptiles are stimulated to learn ecologically relevant behaviours, such as finding shelter from a predator attack (Paulissen, 2008; Noble et al., 2012) or avoiding toxic prey (Ward-Fear et al., 2016; Ko et al., 2020). Several studies have also addressed the aforementioned problem of motivation, either by exploring alternative rewards (access to heat: Day et al., 
2001; preferred food: Mueller-Paul et al., 2012; safety from predator: Noble et al., 2012) or by carefully controlling hunger motivation (e.g., Amiel et al., 2014). An ingenious example of the latter is the study by Emer et al. (2015) where the authors successfully trained Burmese pythons (Python molurus bivitattus) to gradually consume smaller food items (ending at $1 \%$ of their usual prey size). These small food items were then used as rewards in an operant conditioning task, which facilitated more frequent participation of the pythons.

The recent surge of reptilian cognition studies has uncovered that reptiles display a range of cognitive skills (Figures 1 and 2), not inferior to those documented in birds and mammals (Leal \& Powell, 2012). Reptiles exhibit fast and flexible learning, long-term memory, spontaneous problem-solving abilities, quantity discrimination, and even social learning. Font (2020) and Szabo et al. (2021b) provide excellent overviews of the work that has been done on reptilian cognition in the past decades. Here, instead, we focus on the future, by pointing out the potential of reptiles as model species in cognitive research and suggesting an assortment of prospective avenues for future research. Some of these research topics will help us to further understand the (range of) cognitive abilities in reptiles, whilst in other cases reptiles may be used to resolve more general questions regarding the mechanisms, the development, and the evolution of animal cognition. As a token of admiration towards the co-founder of the journal Behaviour, we structured our writing following Tinbergen's four prisms.

\section{Mechanism}

Although we nowadays have a better, albeit still rudimentary, grasp on what reptiles can or cannot learn, we have so far invested very little in understanding how they learn. Let us take spatial cognition as an example. Plenty of recent research has subjected reptiles (although primarily lizards and turtles) to a multitude of spatial learning tasks. Yet, the mechanisms behind spatial learning remain poorly understood. Research in the 2000s and early 2010s already identified a diversity of spatial learning strategies in reptiles, such as response strategies based on egocentric cues (e.g., turn left) (in whiptail lizards: Day et al., 2003; in red-footed tortoises: Mueller-Paul et al., 2012), the use of a local cue (cooccurring with the goal) as guidance (in corn snakes: Holtzman, 1998; in red-eared sliders: López et al., 2000, 2001), remembering multiple distal cues (e.g., features of the experimental room) to form a 

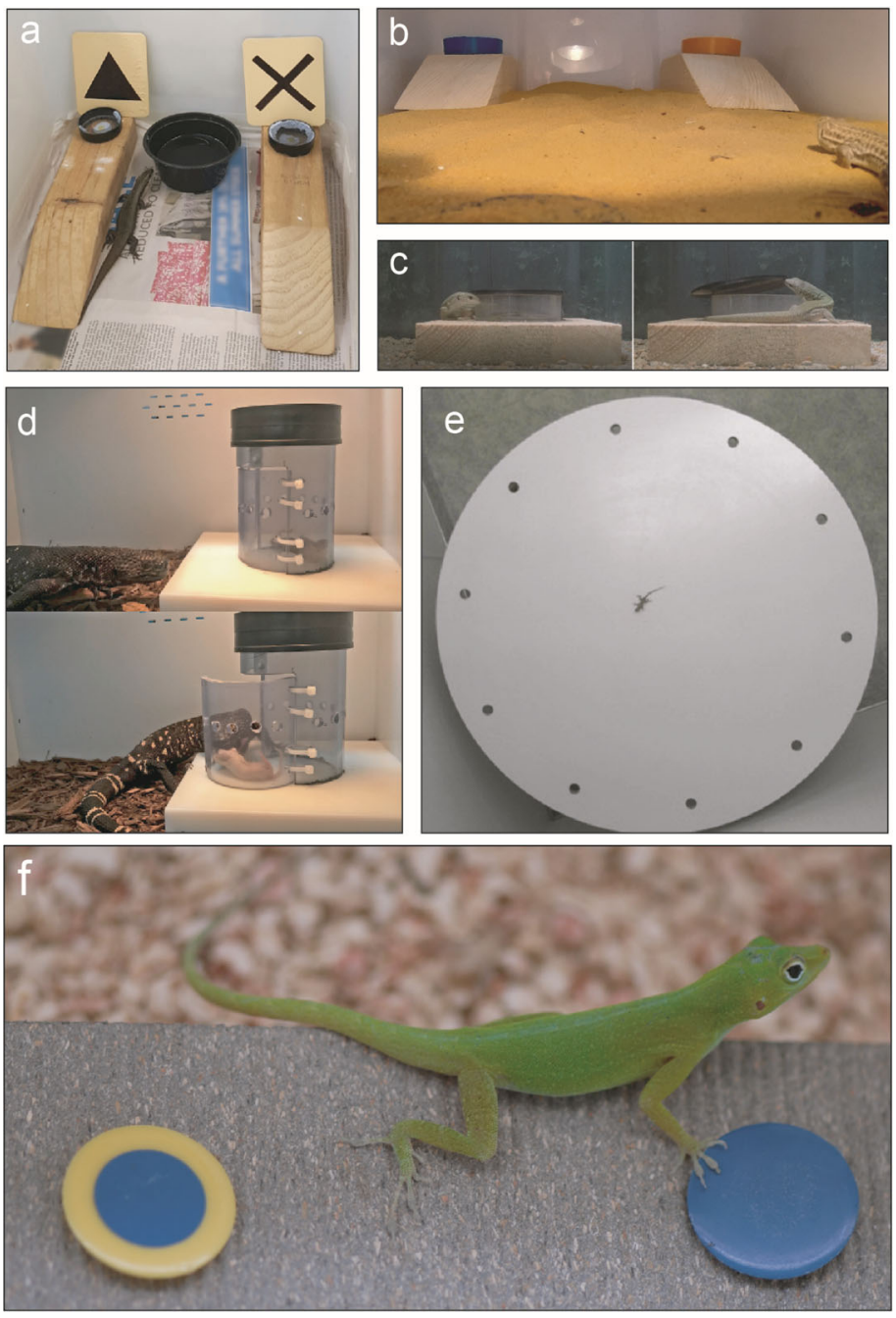

Figure 1. Lizards as focal study animals in cognitive biological research: (a) testing flexibility on a shape discrimination task in tree skinks (Egernia striolata) (from Szabo et al., 2018); (b) a leopard fringe-fingered lizard (Acanthodactylus pardalis) being tested on a colour discrimination task (from De Meester et al., unpublished); (c) a lid-removal task to assess problem-solving ability in Aegean wall lizards (Podarcis erhardii) (from De Meester et al., 2021); (d) a Guatemalan beaded lizard (Heloderma charlesbogerti) solving an extractive foraging task (from Cooper et al., 2019); (e) a Barnes maze to test spatial memory ability and cue use in side-blotched lizards (Uta transburiana) (from Ladage et al., 2012); (f) an anole lizard (Anolis evermanni) performing a colour-based discrimination trial (from Leal \& Powell, 2012). All pictures were reproduced with permission of the original authors. 

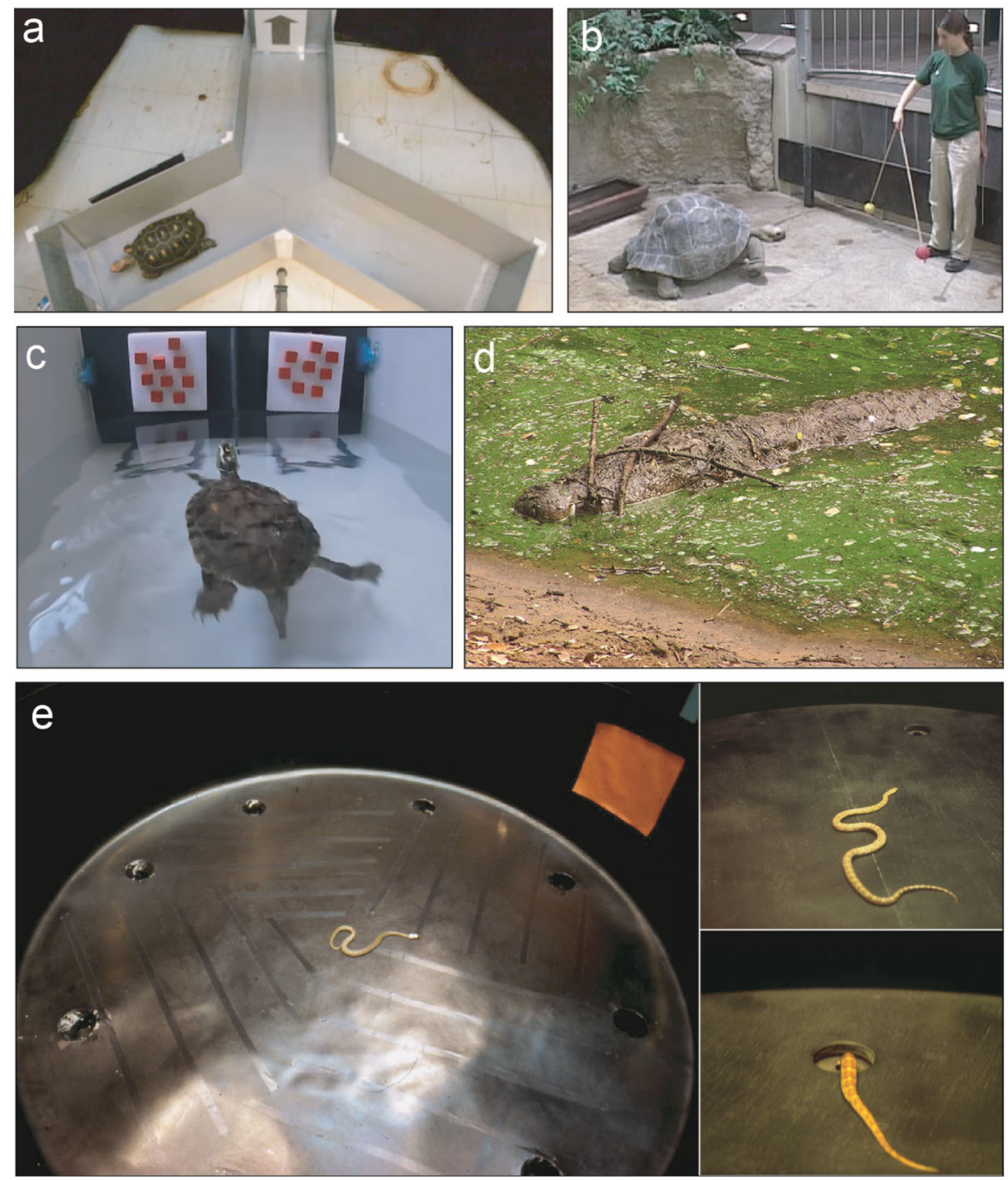

Figure 2. Turtles, snakes, and crocodiles as focal study animals in cognitive biological research: (a) red-footed tortoise (Chelonoidis carbonaria) performing a visual discrimination task in a Y-maze (from Bridgeman \& Tattersall, 2019), (b) Galápagos tortoise (Chelonoidis nigra) trained on a colour discrimination task (from Gutnick et al., 2020), (c) a quantity discrimination test in Chinese stripe-necked turtles (Mauremys sinensis) (from Lin et al., in press); (d) behavioural observations of tool use in a mugger crocodile (Crocodylus palustris) (from Dinets et al., 2013); (e) a juvenile spotted python (Anteresia maculosus) trained to find the location of an escape hole in an arena based on spatial cues (from Stone et al., 2000). All pictures were reproduced with permission of the original authors. 
mental representation of the environment (in red-eared sliders: López et al., 2000, 2001; in side-blotched lizards: Ladage et al., 2012, Figure 1E; in wall lizards: Font, 2019) or a mix of these (in spotted pythons: Stone et al., 2000, Figure 2E). Regardless, even closely-related reptile species can differ considerably in which of these strategies they employ (discussed in depth in Szabo et al., 2021b) and thus this variation (and its ecological relevance) remains poorly understood. In this special issue, Paulissen (2021) specifically tested whether little brown skinks (Scincella lateralis), a species capable of learning the location of a safe hiding spot based on distal (Paulissen, 2008) and local cues (Paulissen, 2014), are also capable of accomplishing the same task using a single positional cue. Paulissen (2021) furthermore discusses the importance of taking into account potential biases for certain cues in future studies on reptilian learning.

Cognition in its broadest sense goes beyond merely acquiring novel information. Cognition is often defined as the perception, acquisition, retention, and use of environmental information (Dukas, 2004). The mechanisms behind that last component, the decision-making process, are even more of an enigma in reptiles than the acquisition process, perhaps because the stereotype of the reptilian 'reflex machine' (sensu Jerison, 1973) remains difficult to debunk. In their contribution to this special issue, Roth et al. (2021) revealed complex interactions between old information and novel environmental cues during the decision-making process in Eastern painted turtles (Chrysemys picta). Subjects previously trained to choose a rewarded arm in a Y-maze, showed to ignore (but not forget) this information and act in a stereotypic way according to a colour or light intensity bias in some cases, while in other cases turtles were clearly capable of overcoming such a bias and rely and act upon their spatial memory. This study illustrates that decision-making in reptiles goes beyond simple stimulus response behaviour, and deserves further attention.

Another promising prospect is the use of reptiles as study models in neurobiology. Once considered structural simple and 'primitive' (Roth et al., 2019; Font, 2020), the reptilian brain is now recognized to govern complex behaviours. The interest of biologists in the neural mechanisms behind reptilian cognition has almost exclusively been focused on spatial cognition, but these studies have revealed neurological processes very similar to those observed in mammals (reviewed in Roth et al., 2019). For example, 
the reptilian medial and dorsal cortices are generally considered to be functional homologues of the mammalian hippocampus (Day et al., 1999, 2001; López et al., 2003a,b; Ladage et al., 2009). Yet much remains to be uncovered on how variation in neuroanatomy (on an inter-specific, -population and -individual level) translates to differences in cognitive abilities (for reptiles and animals in general). Traditionally, studies mainly looked at the (relative) size of brain regions (see, e.g., Day et al., 1999; Ladage et al., 2009), but modern techniques allow researchers to delve deeper into the functional morphology of reptilian brains than ever before. To illustrate with a recent example, using an isotropic fractionator Storks et al. (2020) were able to uncover a potential link between problem-solving ability and the number of non-neuron cells in the brains of two species of Anolis lizards. Albeit small in sample size, their study illustrates how fine-grained measures of brain anatomy can shed new light on the mechanisms behind reptilian cognition. Another topic that warrants further attention is the remarkable high rate of adult neurogenesis in reptilian brains (Powers, 2016; LaDage, 2020). How exactly this may influence cognitive processes in reptiles remains to be investigated. Given this characteristic, reptiles may provide excellent model organisms to study the process of neurogenesis (LaDage, 2020). A third role for reptiles in neuroscience is put forth by Perez-Martinez \& Leal (2021) in their contribution to this special issue. Perez-Martinez \& Leal (2021) propose lizards as a model system to study how the evolution towards extreme small body sizes - a phenomenon dubbed miniaturization - impacts changes in animal brain anatomy, cognitive processes, behaviour, and ecology. In their highly integrative study, Perez-Martinez \& Leal (2021) explore the interface of lizard miniaturization, ecology, and the brain by employing phylogenetic comparative methods, and compare the neuroanatomy of two gecko species that differ dramatically in size (i.e., Sphaerodactylus nicholsi and Gekko smithii) using X-ray microtomography. Such detailed data on the relative proportions of brain regions and neuronal organization, when integrated with animal behaviour, is instrumental in understanding the relationship between brain anatomy and cognition, and ultimately, to comprehend how animals learn.

\section{Ontogeny}

The field of cognitive ecology has recently been zooming in on the causes and consequences of individual variation in cognition (Boogert et al., 2018). 
In that respect, reptiles provide many opportunities to test how early life conditions may impact the development of cognitive abilities. The oviparous nature of many reptiles and overall lack of parental care means that developing reptile embryos are exposed to more variable environmental conditions (such as incubation temperature) compared to birds or mammals (Shine, 1980, 1983, 2005; Gans, 1996). Researchers can easily manipulate one or multiple factors during development to study how these affect cognitive development. Indeed, this opportunity has been eagerly exploited to study how deviations in incubation temperature affect brain and cognitive development in lizards (three-lines skinks: Clark et al., 2013; Amiel et al., 2014, 2017; bearded dragons: Siviter et al., 2017; velvet geckoes: Dayananda \& Webb, 2017; Abayarathna \& Webb, 2020; three-toed skinks: Beltrán et al., 2020), a topic of concern in the light of the current, unprecedented, change in global climate (reviewed in Beltrán et al., 2021).

While it is well studied how social isolation affects cognitive development in obligate social species (e.g., brown rats: Morgan et al., 1975), less is known about its impact on species with more facultative social systems. Reptiles exhibit a relative diverse spectrum of social strategies throughout their entire phylogeny (both inter- and intraspecific), but even the more complex forms (e.g., family-living) are often temporary or facultative at best (Doody et al., 2013; Whiting \& While, 2017). It is therefore interesting to study whether social influences have a different impact on their cognitive development, as this will help us to further understand the earlier stages of evolution towards more permanent sociality in other groups (Munch et al., 2018b; Riley et al., 2018). Three studies have tackled this topic in family-living lizards, two of which reported no effect of isolation on juvenile learning ability (tree skinks: Riley et al., 2017, 2018) and one study finding that maternal presence during early life improved juvenile spatial learning performance (White's skinks: Munch et al., 2018b).

Other studies have focused on the influence of pre- and post-natal food availability (White's skinks: Munch et al., 2018a), embryonic light-exposure and oxygen availability (Mongolian racerunner lizards: Sun et al., 2014; Li et al., 2019) and captivity (delicate skinks: Vardi et al., 2020) on cognitive development, but this represents just the tip of the iceberg of potential questions that could be addressed.

Reptiles also differ from more traditional study species in the sense that they are precocial, which raises interesting questions regarding the ontogeny 
of their cognitive abilities. Without the protection of parental care (in most species at least, Whiting \& While, 2017), one would expect reptiles to be fully cognitively developed at birth. The effect of age on cognition has only been studied in two reptile species (i.e. C. picta and Tiliqua scincoides) so far. In Eastern painted turtles (C. picta), there is a critical period in which juveniles are able to learn the migration routes between two ponds (Roth \& Krochmal, 2015, 2018). Chemically disruption of spatial memory, through administration of an acetylcholine receptor antagonist, in juvenile turtles ( $<3$ years old) does not impact their ability to navigate between two ponds, likely because they follow environmental (UV-) cues during migration. Turtles older than four years do rely on spatial memory, as supported by the fact that the same memory-blocking drug disrupts their navigation during migration. Interestingly, three-year old turtles injected with this memoryblocking drug are unable to follow the same migration route in the subsequent year, demonstrating the existence of a critical learning period in this species (Roth \& Krochmal, 2018). Such differences in behavioural flexibility between juveniles and adults were not observed in a study on blue-tongued skinks (T. scincoides) (Szabo et al., 2019a). More work is needed to further understand how the importance and capacity to learn ecological relevant information changes throughout the life of an individual reptile.

\section{Function}

Clearly, cognition plays an important role in many aspects of an individual's life. Through problem-solving and learning, animals are capable of adjusting their behaviour to a myriad of environmental challenges (Sol, 2009). Therefore, one would intuitively believe that cognition is beneficial, although empirical evidence for (or against) this idea is currently ambiguous.

One approach to uncover the adaptive value and function of cognition, is by understanding how certain cognitive skills relate to ecological relevant behaviour of wild animals in a natural setting. For example, the adaptive value of spatial memory in several food-hoarding bird species is wellunderstood, as a clear role of spatial memory in cache retrieval has been documented (Smulders et al., 2010). Very few studies so far have investigated the role of reptilian cognition in a natural setting. The previously described studies of Roth \& Krochmal $(2015,2018)$ did indeed confirm the importance of spatial memory for successful migration in adult Eastern painted 
turtles. The adaptive value of learning new information is also highlighted by Ward-Fear et al. (2016), reporting on how Australian yellow-spotted monitor lizards (Varanus panoptes) were successfully trained to avoid invasive and highly toxic cane toads (Rhinella marina) via conditioned taste aversion. Trained lizards subsequently survived longer compared to untrained conspecifics when the cane toads arrived in their habitat (Ward-Fear et al., 2016). Yet, how cognition measured in the lab translates to behaviour in the wild remains speculative for most reptile species.

Other researchers, however, tend to determine the adaptive value of cognition by following a more individual-based approach. A small, yet increasing, number of studies have now investigated how individual variation in cognition relates to variation in survival or reproductive success, often yielding mixed results (see, e.g., Cole et al., 2012; Maille \& Schradin, 2016; Preiszner et al., 2017; Madden et al., 2018; Sonnenberg et al., 2019). Nevertheless, most of these studies were done on birds, and only a single one has investigated selection on cognition in a reptile: hatchling velvet geckoes (Amalosia lesuerii) with a superior spatial memory were more likely to survive in the wild over a course of eight months than conspecifics with an inferior spatial memory (Dayananda \& Webb, 2017); how exactly spatial cognition contributed to the survival of these hatchlings was not investigated.

Another promising avenue is the role of sexual selection as a driver of cognitive diversification. Sexual selection is often considered the reason for sex-differences in cognition, as males may require stronger spatial cognition in order to navigate over larger distances to find females, or have to remember and defend the boundaries of (larger) territories (Carazo et al., 2014; Szabo et al., 2019b). Although so far evidence of sex-dependent learning is weak in reptiles (Szabo et al., 2019b), it would be interesting to compare females and males across a range of reptile species that endure disparate intensities of sexual selection. In non-reptilian taxa, it has been shown that both male (Keagy et al., 2009; Shohet \& Watt, 2009; Chen et al., 2019) and female (Álvarez-Quintero et al., 2021) cognitive ability can affect female mate choice. Learning and memory can play an important role in rival assessment and contest outcome, which in turn may bear important consequences for mating success (Reichert \& Quinn, 2017). Interestingly, sexual selection on cognitive ability can also differ within a species depending on the mating strategy adopted by a male (Smith et al., 2015). These questions are also relevant for reptiles, and thus deserve further attention. 


\section{Phylogeny}

Many biologists have lamented how the vast taxonomic bias towards a select number of (mammalian and avian) species in animal cognition studies has severely impaired our understanding of its evolution (Shettleworth, 2009). In our venture to achieve a complete understanding of cognitive evolution, it is absolutely instrumental to include those species that are currently underrepresented in cognition research. The phylogenetic position of nonavian reptiles relative to mammals and birds (Irisarri et al., 2017) can help us to unravel whether similarities in cognitive skills between the two latter taxa are the results of convergent evolution or shared ancestry, and to what degree the evolution of cognition is predictable. This does require, of course, a more complete understanding of what reptiles are or are not capable of. For instance, numerical discrimination (i.e. the ability to distinguish larger from smaller quantities) has been reported in all classes of vertebrates (Agrillo \& Bisazza, 2017), yet, for a long time it was unclear whether reptiles possessed this ability as well. Recent efforts surprisingly show that Italian wall lizards (Podarcis siculus) lack spontaneous quantity discrimination and learn numerical rules relatively poorly even after extensive training (Miletto Petrazzini et al., 2017, 2018). Nevertheless, other studies do demonstrate spontaneous quantity discrimination in the closely-related Carpetan rock lizard (Iberolacerta cyreni, Recio et al., 2021), gidgee skinks (Egernia stokessi, Szabo et al., 2021a), in Hermann's tortoises (Testudo hermanni, Gazzola et al., 2018) and Chinese stripe-necked turtles (Mauremys sinensis, Lin et al., in press, Figure 2C). Given the limited number of species tested on numerical cognition, its evolution throughout the reptile and vertebrate phylogeny remains disputed.

It is worth noting that feats once considered unique for mammals (particularly primates), such as tool use or self-recognition in a mirror, are now being reported more frequently in birds and other taxa too (Healy, 2019). Indeed, tool use was recently documented for the first time in reptiles. Dinets et al. (2013) described how swimming mugger crocodiles (Crocodylus palustris) and American alligators (Alligator mississippiensis) display sticks and twigs on their snout in order to lure nest-building birds (Figure 2D). Systematic observations revealed that this 'stick-displaying' behaviour was only observed during the breeding season of nearby rookeries of birds. And while lizards do not appear to recognize themselves in a mirror (Scali et al., 2019), they do seem to be capable of discriminating between their own scent and 
those of conspecifics (e.g., Liolaemus sp.: Aguilar et al., 2008; common wall lizards: Mangiacotti et al., 2019; Trogonophis wiegmanni: Martín et al., 2020). In their contribution to this special issue, Burghardt et al. (2021) raise the question of whether garter snakes (Thamnophis sirtalis) are capable of chemical self-recognition, and review the broader evidence for the presence of this ability in squamates. Their study, as well as the previous mentioned example of tool-use in crocodilians, stresses the importance of expanding comparative cognitive research towards more non-traditional study species. After all, understanding how our own human technological skill and selfawareness came to be, starts with verifying whether and to which extent non-human animals possess similar abilities.

But even within reptiles, the phylogeny of cognition is poorly understood. Whether and how the major lineages differ in cognitive abilities, or how much variation even exists among closely related species is currently difficult to grasp due to the lack of comparative work (Wilkinson \& Huber, 2012). Krochmal et al. (2018) found that seven species of rattlesnakes all uniformly and consistently habituated to a thermal maze after a single trial, while none of the six non-rattlesnake pit viper species decreased their latency to make a decision in the maze across twelve trials. Another study showed that three species of monitor lizards all learnt a problem-solving task (Figure 1D) faster than the closely-related Guatemalan beaded lizard (Heloderma charlesbogerti) which the authors contributed to the active foraging style of monitor lizards (Cooper et al., 2019). In contrast to Krochmal et al. (2018), however, Cooper and colleagues reported considerable variation among and within species. Similarly, at a more narrow taxonomic scale, Szabo et al. (2020) also demonstrated that five closely related species of Australian skinks (Egernia group) differed in their performance on a classical detour task.

Comparative studies also provide a powerful tool to identify the social and ecological drivers of cognitive evolution, and can thus help to provide further insights in the adaptive value of (specific) cognitive skills (MacLean et al., 2012). Here, researchers typically sample multiple species or populations differing in one or a few aspects of their biology, such as diet or mating strategy. It is then tested whether variation in cognitive performance or brain anatomy among these groups can be related to differences in this ecological variable (see review in Henke-von der Malsburg et al., 2020). Likewise, in this special issue De Meester et al. (2021) aimed to test two 
conflicting hypotheses regarding the effect of environmental variability on behavioural flexibility in Aegean wall lizards (Podarcis erhardii). To do so, the authors compared the performance of lizards originating from an island (high environmental variability in resources) and a mainland population (more stable resources) on an array of cognitive tasks (Figure 1C). Other studies have conducted similar comparisons with lizards, to examine the effect of foraging style (two species of fringe-fingered lizards: Day et al., 1999), urbanization (delicate skinks: Kang et al., 2018; Indian rock agamas: Batabyal \& Thaker, 2019), sociality and habitat unpredictability (sleepy lizards and blue-tongue skinks: Szabo \& Whiting, 2020), invasiveness (two species of sunskinks: Bezzina et al., 2014) and territory harshness (Tropidurus catalanensis: Rodrigues \& Kohlsdorf, 2019). Due to their taxonomic richness (approximately 11400 species: Uetz et al., 2021) and ecological diversity (Vitt \& Caldwell, 2014) reptiles offer ample opportunities for further research on the environmental pressures that have driven the evolution of animal cognition.

\section{To summarise}

The questions proposed above are far from exhaustive, but mainly serve to illustrate the immense potential of reptiles as a model system. With this special issue, we hence hope to further contribute to debunk the 'dumb reptile' stereotype, and steer towards their total inclusion in cognitive research. This will not only improve our understanding of reptilian cognition itself (which could yield important consequences for conservation and animal welfare) but is also bound to pay off with more general insights in the mechanisms, function, and evolution of cognition throughout the animal kingdom. With much remaining to be discovered, there has never been a better time than now to study reptile cognition.

\section{Acknowledgements}

We are grateful to the journal editors for the opportunity to guest edit this special issue. We also thank all authors and reviewers for their excellent contributions, Raoul Van Damme for feedback on an earlier draft of this editorial, and, Birgit Szabo, Mathieu Pierret, Joseph Mendelson, Lara LaDage, Manuel Leal, Glenn J. Tattersall, Michael J. Kuba, Si-Min Lin, David A. Holtzman and Vladimir Dinets for enthusiastically sharing pictures of their 
research. This work was supported by the Flemish Foundation - Flandres (FWO) through a PhD fellowship (to GDM, ID: 1144118N) and a junior postdoc fellowship (to SB: 12I8819N).

\section{References}

Abayarathna, T. \& Webb, J.K. (2020). Effects of incubation temperatures on learning abilities of hatchling velvet geckos. - Anim. Cogn. 23: 613-620.

Agrillo, C. \& Bisazza, A. (2017). Understanding the origin of number sense: a review of fish studies. — Philos. Trans. Roy. Soc. Lond. B: Biol. Sci. 373: 20160511.

Aguilar, P.M., Labra, A. \& Niemeyer, H.M. (2008). Chemical self-recognition in the lizard Liolaemus fitzgeraldi. - J. Ethol. 27: 181-184.

Álvarez-Quintero, N., Velando, A., Kim, S.-Y. \& Candolin, U. (2021). Smart mating: the cognitive ability of females influences their preference for male cognitive ability. - Behav. Ecol.: arab052.

Amiel, J.J., Lindstrom, T. \& Shine, R. (2014). Egg incubation effects generate positive correlations between size, speed and learning ability in young lizards. - Anim. Cogn. 17: 337-347.

Amiel, J.J., Bao, S. \& Shine, R. (2017). The effects of incubation temperature on the development of the cortical forebrain in a lizard. - Anim. Cogn. 20: 117-125.

Batabyal, A. \& Thaker, M. (2019). Lizards from suburban areas learn faster to stay safe. Biol. Lett. 15: 20190009.

Beltrán, I., Loiseleur, R., Durand, V. \& Whiting, M.J. (2020). Effects of early thermal environment on the behavior and learning of a lizard with bimodal reproduction. - Behav. Ecol. Sociobiol. 74: 1-13.

Beltrán, I., Herculano-Houzel, S., Sinervo, B. \& Whiting, M.J. (2021). Are ectotherm brains vulnerable to global warming?. — Trends Ecol. Evol. 36: 691-699.

Bezzina, C.N., Amiel, J.J. \& Shine, R. (2014). Does invasion success reflect superior cognitive ability? A case study of two congeneric lizard species (Lampropholis, Scincidae). PLoS ONE 9: e86271.

Boogert, N.J., Madden, J.R., Morand-Ferron, J. \& Thornton, A. (2018). Measuring and understanding individual differences in cognition. - Philos. Trans. Roy. Soc. Lond. B: Biol. Sci. 373: 20170280.

Bridgeman, J.M. \& Tattersall, G.J. (2019). Tortoises develop and overcome position biases in a reversal learning task. — Anim. Cogn. 22: 265-275.

Burghardt, G.M. (1977). Learning processes in reptiles. — In: Biology of the Reptilia: ecology and behaviour A (Gans, C. \& Tinkle, D.W., eds). Academic Press, London, p. 555681.

Burghardt, G.M., Partin, A.M., Pepper, H.E., Steele, J.M., Liske, S.M., Stokes, A.E., Lathan, A.N., Springer, C.M. \& Jenkins, M.S. (2021). Chemically mediated self-recognition in sibling juvenile common gartersnakes (Thamnophis sirtalis) reared on same or different diets: evidence for a chemical mirror? — Behaviour 158: 1169-1191. DOI:10.1163/ 1568539X-bja10131. 
Carazo, P., Noble, D.W., Chandrasoma, D. \& Whiting, M.J. (2014). Sex and boldness explain individual differences in spatial learning in a lizard. - Proc. Royal Soc. B. 281: 20133275.

Chen, J., Zou, Y., Sun, Y.H. \& Ten Cate, C. (2019). Problem-solving males become more attractive to female budgerigars. - Science 363: 166-167.

Clark, B.F., Amiel, J.J., Shine, R., Noble, D.W.A. \& Whiting, M.J. (2013). Colour discrimination and associative learning in hatchling lizards incubated at 'hot' and 'cold' temperatures. - Behav. Ecol. Sociobiol. 68: 239-247.

Cole, E.F., Morand-Ferron, J., Hinks, A.E. \& Quinn, J.L. (2012). Cognitive ability influences reproductive life history variation in the wild. - Curr. Biol. 22: 1808-1812.

Cookson, J.H. (1962). Failure of lizards to learn a simple task. — Brit. J. Herpetol. 3: 40.

Cooper, T., Liew, A., Andrle, G., Cafritz, E., Dallas, H., Niesen, T., Slater, E., Stockert, J., Vold, T., Young, M. \& Mendelson, J. (2019). Latency in problem solving as evidence for learning in varanid and helodermatid lizards, with comments on foraging techniques. Copeia 107: 78-84.

Day, L.B., Crews, D. \& Wilczynski, W. (1999). Spatial and reversal learning in congeneric lizards with different foraging strategies. - Anim. Beh. 57: 393-407.

Day, L.B., Crews, D. \& Wilczynski, W. (2001). Effects of medial and dorsal cortex lesions on spatial memory in lizards. - Behav. Brain. Res. 118: 27-42.

Day, L.B., Ismail, N. \& Wilczynski, W. (2003). Use of position and feature cues in discrimination learning by the whiptail lizard (Cnemidophorus inornatus). - J. Comp. Psychol. 117: 440-448.

Dayananda, B. \& Webb, J.K. (2017). Incubation under climate warming affects learning ability and survival in hatchling lizards. - Biol. Lett. 13: 20170002.

De Meester, G., Sfendouraki-Basakarou, A., Pafilis, P. \& Van Damme, R. (2021). Dealing with the unexpected: the effect of environmental variability on behavioural flexibility in a Mediterranean lizard. — Behaviour 158: 1193-1223. DOI:10.1163/1568539X-bja10088.

Dinets, V., Brueggen, J.C. \& Brueggen, J.D. (2013). Crocodilians use tools for hunting. Ethol. Ecol. Evol. 27: 74-78.

Doody, J.S., Burghardt, G.M. \& Dinets, V. (2013). Breaking the social-non-social dichotomy: a role for reptiles in vertebrate social behavior research? - Ethology 119: 95-103.

Dukas, R. (2004). Evolutionary biology of animal cognition. - Annu. Rev. Ecol. Evol. Syst. 35: 347-374.

Emer, S.A., Mora, C.V., Harvey, M.T. \& Grace, M.S. (2015). Predators in training: operant conditioning of novel behavior in wild Burmese pythons (Python molurus bivitattus). Anim. Cogn. 18: 269-278.

Font, E. (2019). Rapid learning of a spatial memory task in a lacertid lizard (Podarcis liolepis). — Behav. Process. 169: 103963.

Font, E. (2020). Squamate cognition. - In: Encyclopedia of animal cognition and behavior (Shackelford, T. \& Vonk, J., eds). Springer, Berlin, p. 1-10.

Gans, C. (1996). An overview of parental care among the Reptilia. — Adv. Stud. Behav. 25: 145-157. 
Gazzola, A., Vallortigara, G. \& Pellitteri-Rosa, D. (2018). Continuous and discrete quantity discrimination in tortoises. - Biol. Lett. 14: 20180649.

Gutnick, T., Weissenbacher, A. \& Kuba, M.J. (2020). The underestimated giants: operant conditioning, visual discrimination and long-term memory in giant tortoises. - Anim. Cogn. 23: 159-167.

Healy, S.D. (2019). The face of animal cognition. - Integr. Zool. 14: 132-144.

Henke-Von Der Malsburg, J., Kappeler, P.M. \& Fichtel, C. (2020). Linking ecology and cognition: does ecological specialisation predict cognitive test performance? - Behav. Ecol. Sociobiol. 74: 1-26.

Holtzman, D.A. (1998). From slither to hither: orientation and spatial learning in snakes. Integr. Biol. 1: 81-89.

Irisarri, I., Baurain, D., Brinkmann, H., Delsuc, F., Sire, J.Y., Kupfer, A., Petersen, J., Jarek, M., Meyer, A., Vences, M. \& Philippe, H. (2017). Phylotranscriptomic consolidation of the jawed vertebrate timetree. - Nature Ecol. Evol. 1: 1370-1378.

Jerison, H.J. (1973). Evolution of the brain and intelligence. — Academic Press, New York, NY.

Kang, F., Goulet, C.T. \& Chapple, D.G. (2018). The impact of urbanization on learning ability in an invasive lizard. - Biol. J. Linn. Soc. 123: 55-62.

Keagy, J., Savard, J.-F. \& Borgia, G. (2009). Male satin bowerbird problem-solving ability predicts mating success. - Anim. Beh. 78: 809-817.

Ko, Y.-W., Liao, C.-P., Clark, R.W., Hsu, J.-Y., Tseng, H.-Y. \& Huang, W.-S. (2020). Aposematic coloration of prey enhances memory retention in an agamid lizard. - Anim. Beh. 161: 1-13.

Krochmal, A.R., Place, A.J., Laduc, T.J. \& Roth, T.C. (2018). Phylogenetic patterns in learning and decision making in pit vipers (Viperidae: Crotalinae). - Anim. Beh. 145: 117-123.

LaDage, L.D. (2020). Broadening the functional and evolutionary understanding of postnatal neurogenesis using reptilian models. - J. Exp. Biol. 223: jeb210542.

LaDage, L.D., Riggs, B.J., Sinervo, B. \& Pravosudov, V.V. (2009). Dorsal cortex volume in male side-blotched lizards (Uta stansburiana) is associated with different space use strategies. - Anim. Beh. 78: 91-96.

LaDage, L.D., Roth, T.C., Cerjanic, A.M., Sinervo, B. \& Pravosudov, V.V. (2012). Spatial memory: are lizards really deficient? — Biol. Lett. 8: 939-941.

Leal, M. \& Powell, B.J. (2012). Behavioural flexibility and problem-solving in a tropical lizard. - Biol. Lett. 8: 28-30.

Li, X., Wang, C., Tang, G., Li, S., Ma, L., Sun, B.J. \& Zhang, Y. (2019). Does light exposure during embyronic development affect cognitive behavior in a lizard. - Asian Herpetol. Res. 11: 56-62.

Lin, F.-C., Whiting, M.J., Hsieh, M.-Y., Shaner, P.-J.L. \& Lin, S.-M. (2021). Superior continuous quantity discrimination in a freshwater turtle. - Front. Zool.: in press. DOI:10. 1186/s12983-021-00431-y.

López, J.C., Rodriguez, F., Gómez, Y., Vargas, J.P., Broglio, C. \& Salas, C. (2000). Place and cue learning in turtles. — Anim. Learn. Behav. 4: 360-372. 
López, J.C., Gómez, Y., Rodriguez, F., Broglio, C., Vargas, J.P. \& Salas, C. (2001). Spatial learning in turtles. - Anim. Cogn. 4: 49-59.

López, J.C., Gómez, Y., Vargas, J.P. \& Salas, C. (2003a). Spatial reversal learning deficit after medial cortex lesion in turtles. - Neurosci. Lett. 341: 197-200.

López, J.C., Vargas, J.P., Gómez, Y. \& Salas, C. (2003b). Spatial and non-spatial learning in turtles: the role of medial cortex. — Behav. Brain. Res. 143: 109-120.

Maclean, E.L., Matthews, L.J., Hare, B.A., Nunn, C.L., Anderson, R.C., Aureli, F., Brannon, E.M., Call, J., Drea, C.M., Emery, N.J., Haun, D.B.M., Herrmann, E., Jacobs, L.F., Platt, M.L., Rosati, A.G., Sandel, A.A., Schroepfer, K.K., Seed, A.M., Tan, J., van Schaik, C.P. \& Wobber, V. (2012). How does cognition evolve? Phylogenetic comparative psychology. - Anim. Cogn. 15: 223-238.

Madden, J.R., Langley, E.J.G., Whiteside, M.A., Beardsworth, C.E. \& Van Horik, J.O. (2018). The quick are the dead: pheasants that are slow to reverse a learned association survive for longer in the wild. - Philos. Trans. Roy. Soc. Lond. B: Biol. Sci. 373: 20170297.

Maille, A. \& Schradin, C. (2016). Survival is linked with reaction time and spatial memory in African striped mice. — Biol. Lett. 12: 20160346.

Mangiacotti, M., Gaggiani, S., Coladonato, A.J., Scali, S., Zuffi, M.A.L. \& Sacchi, R. (2019). First experimental evidence that proteins from femoral glands convey identity-related information in a lizard. - Acta Ethol. 22: 57-65.

Martín, J., Raya Garcia, E., Ortega, J. \& Lopez, P. (2020). How to maintain underground social relationships? Chemosensory sex, partner and self recognition in a fossorial amphisbaenian. - PLoS ONE 15: e0237188.

Miletto Petrazzini, M.E., Fraccaroli, I., Gariboldi, F., Agrillo, C., Bisazza, A., Bertolucci, C. \& Foa, A. (2017). Quantitative abilities in a reptile (Podarcis sicula). — Biol. Lett. 13: 20160899.

Miletto Petrazzini, M.E., Bertolucci, C. \& Foa, A. (2018). Quantity discrimination in trained lizards (Podarcis sicula). — Front. Psychol. 9: 274.

Morgan, M.J., Einon, D.F. \& Nicholas, D. (1975). The effects of isolation rearing on behavioural inhibition in the rat. - Q. J. Exp. Psychol. 27: 615-634.

Mueller-Paul, J., Wilkinson, A., Hall, G. \& Huber, L. (2012). Radial-arm-maze behavior of the red-footed tortoise (Geochelone carbonaria). - J. Comp. Psychol. 126: 305-317.

Munch, K.L., Noble, D.W.A., Botterill-James, T., Koolhof, I.S., Halliwell, B., Wapstra, E. \& While, G.M. (2018a). Maternal effects impact decision-making in a viviparous lizard. Biol. Lett. 14: 1298-1306.

Munch, K.L., Noble, D.W.A., Budd, L., Row, A., Wapstra, E. \& While, G.M. (2018b). Maternal presence facilitates plasticity in offspring behavior: insights into the evolution of parental care. - Behav. Ecol. 29: 1298-1306.

Noble, D.W., Carazo, P. \& Whiting, M.J. (2012). Learning outdoors: male lizards show flexible spatial learning under semi-natural conditions. — Biol. Lett. 8: 946-948.

Paulissen, M.A. (2008). Spatial learning in the little brown skink, Scincella lateralis: the importance of experience. - Anim. Behav. 76: 135-141. 
Paulissen, M.A. (2014). The role of visual cues in learning escape behaviour in the little brown skink (Scincella lateralis). — Behaviour 151: 2015-2028.

Paulissen, M.A. (2021). Pattern biases, but not positional cues, influence learning in the little brown skink, Scincella lateralis. — Behaviour 158: 1077-1099. DOI:10.1163/1568539Xbja10090.

Perez-Martinez, C.A. \& Leal, M. (2021). Lizards as models to explore the ecological and neurophysiological correlates of miniaturization. - Behaviour 158: 1121-1168. DOI:10. 1163/1568539X-bja10104.

Pettit, L., Ward-Fear, G. \& Shine, R. (2021). Invasion of cane toads (Rhinella marina) affects the problem-solving performance of vulnerable predators (monitor lizards, Varanus varius). - Behav. Ecol. Sociobiol. 75: 39.

Powers, A.S. (2016). Plasticity and adult neurogenesis in amphibians and reptiles: more questions than answers. - Brain. Behav. Evol. 87: 175-183.

Preiszner, B., Papp, S., Pipoly, I., Seress, G., Vincze, E., Liker, A. \& Bokony, V. (2017). Problem-solving performance and reproductive success of great tits in urban and forest habitats. - Anim. Cogn. 20: 53-63.

Recio, P., Rodríguez-Ruiz, G., López, P. \& Martín, J. (2021). Prey quantity discrimination and social experience affect foraging decisions of rock lizards. - Behav. Ecol. Sociobiol. 75: 33 .

Reichert, M.S. \& Quinn, J.L. (2017). Cognition in contests: mechanisms, ecology, and evolution. - Trends Ecol. Evol. 32: 773-785.

Riley, J.L., Küchler, A., Damasio, T., Noble, D.W.A., Byrne, R.W. \& Whiting, M.J. (2018). Learning ability is unaffected by isolation rearing in a family-living lizard. - Behav. Ecol. Sociobiol. 72: 20.

Riley, J.L., Noble, D.W.A., Byrne, R.W. \& Whiting, M.J. (2017). Does social environment influence learning ability in a family-living lizard? - Anim. Cogn. 20: 449-458.

Robin, E.D. (1973). The evolutionary advantages of being stupid. - Perspect. Biol. Med. 16: 369-380.

Rodrigues, A.V. \& Kohlsdorf, T. (2019). Learning skills in Tropidurus lizards are associated with territory harshness. - J. Zool. 309: 250-258.

Roth, A.D., Krochmal, A.R. \& Roth, T.C. (2021). Context-specific cue use in the eastern painted turtle (Chrysemys picta) and its effects on decision making. - Behaviour 158: 1101-1120. DOI:10.1163/1568539X-bja10093.

Roth, T.C. \& Krochmal, A.R. (2015). The role of age-specific learning and experience for turtles navigating a changing landscape. - Curr. Biol. 25: 333-337.

Roth, T.C. \& Krochmal, A.R. (2018). Of molecules, memories and migration: M1 acetylcholine receptors facilitate spatial memory formation and recall during migratory navigation. — Proc. Roy. Soc. Lond. B: Biol. Sci. 285: 20181904.

Roth, T.C., Krochmal, A.R. \& Ladage, L.D. (2019). Reptilian cognition: a more complex picture via integration of neurological mechanisms, behavioral constraints, and evolutionary context. - Bioessays 41: e1900033. 
Scali, S., Sacchi, R., Falaschi, M., Coladonato, A.J., Pozzi, S., Zuffi, M.A.L. \& Mangiacotti, M. (2019). Mirrored images but not silicone models trigger aggressive responses in male common wall lizards. - Acta Herpetol. 14: 35-41.

Shettleworth, S.J. (2009). The evolution of comparative cognition: is the snark still a boojum?. — Behav. Process. 80: 210-217.

Shine, R. (1980). "Costs" of reproduction in reptiles. — Oecologia 46: 92-100.

Shine, R. (1983). Reptilian reproductive modes: the oviparity-viviparity continuum. — Herpetologica 39: 1-8.

Shine, R. (2005). Life-history evolution in reptiles. - Annu. Rev. Ecol. Evol. Syst. 36: 23-46.

Shohet, A.J. \& Watt, P.J. (2009). Female guppies Poecilia reticulata prefer males that can learn fast. — J. Fish Biol. 75: 1323-1330.

Siviter, H., Deeming, D.C., Van Giezen, M.F.T. \& Wilkinson, A. (2017). Incubation environment impacts the social cognition of adult lizards. — Roy. Soc. Open. Sci. 4: 170742.

Smith, C., Philips, A. \& Reichard, M. (2015). Cognitive ability is heritable and predicts the success of an alternative mating tactic. - Proc. Roy. Soc. Lond. B: Biol. Sci. 282: 20151046.

Smulders, T.V., Gould, K.L. \& Leaver, L.A. (2010). Using ecology to guide the study of cognitive and neural mechanisms of different aspects of spatial memory in food-hoarding animals. — Philos. Trans. Roy. Soc. Lond. B: Biol. Sci. 365: 883-900.

Sol, D. (2009). Revisiting the cognitive buffer hypothesis for the evolution of large brains. Biol. Lett. 5: 130-133.

Sonnenberg, B.R., Branch, C.L., Pitera, A.M., Bridge, E. \& Pravosudov, V.V. (2019). Natural selection and spatial cognition in wild food-caching mountain chickadees. - Curr. Biol. 29: 670-676 e3.

Stone, A., Ford, N.B. \& Holtzman, D.A. (2000). Spatial learning and shelter selection by juvenile spotted pythons, Anteresia maculosus. — J. Herpetol. 34: 575-587.

Storks, L., Powell, B.J. \& Leal, M. (2020). Peeking inside the lizard brain: neuron numbers in anolis and its implications for cognitive performance and vertebrate brain evolution. Integr. Comp. Biol.: icaa129.

Sun, B.J., Wang, T.T., Pike, D.A., Liang, L. \& Du, W.G. (2014). Embryonic oxygen enhances learning ability in hatchling lizards. — Front. Zool. 11: 1-8.

Szabo, B. \& Whiting, M.J. (2020). Do lizards have enhanced inhibition? A test in two species differing in ecology and sociobiology. — Behav. Process. 172: 104043.

Szabo, B., Noble, D.W.A., Byrne, R.W., Tait, D.S. \& Whiting, M.J. (2018). Subproblem learning and reversal of a multidimensional visual cue in a lizard: evidence for behavioural flexibility? - Anim. Behav. 144: 17-26.

Szabo, B., Noble, D.W.A., Byrne, R.W., Tait, D.S. \& Whiting, M.J. (2019a). Precocial juvenile lizards show adult level learning and behavioural flexibility. - Anim. Behav. 154: 75-84.

Szabo, B., Whiting, M.J. \& Noble, D.W.A. (2019b). Sex-dependent discrimination learning in lizards: a meta-analysis. — Behav. Process. 164: 10-16. 
Szabo, B., Hoefer, S. \& Whiting, M.J. (2020). Are lizards capable of inhibitory control? Performance on a semi-transparent version of the cylinder task in five species of Australian skinks. - Behav. Ecol. Sociobiol. 74: 118.

Szabo, B., Noble, D.W.A., Mccloghry, K.J., Monteiro, M.E.S., Whiting, M.J. \& Ridley, A. (2021a). Spontaneous quantity discrimination in a family-living lizard. - Behav. Ecol. 32: 686-694.

Szabo, B., Noble, D.W.A. \& Whiting, M.J. (2021b). Learning in non-avian reptiles 40 years on: advances and promising new directions. - Biol. Rev. 96: 331-356.

Turner, C.H. (1892). A few characteristics of the avian brain. - Science 19: 16-17.

Uetz, P., Freed, P., Aguilar, R. \& Hošek, J. (2021). The reptile database. Available online at http://www.reptile-database.org/.

Vardi, R., Goulet, C.T., Matthews, G., Berger-Tal, O., Wong, B.B.M. \& Chapple, D.G. (2020). Spatial learning in captive and wild-born lizards: heritability and environmental effects. - Behav. Ecol. Sociobiol. 74: 23.

Vitt, L.J. \& Caldwell, J.P. (2014). Herpetology: an introductory biology of amphibians and reptiles. - Academic Press, Cambridge.

Ward-Fear, G., Pearson, D.J., Brown, G.P., Rangers, B. \& Shine, R. (2016). Ecological immunization: in situ training of free-ranging predatory lizards reduces their vulnerability to invasive toxic prey. - Biol. Lett. 12: 20150863.

Whiting, M.J. \& Noble, D.W. (2018). Lizards - measuring cognition: practical challenges and the influence of ecology and social behaviour. - In: Field and laboratory methods in animal cognition (Bueno-Guerra, N. \& Amici, F., eds). Cambridge University Press, Cambridge, p. 266-285.

Whiting, M.J. \& While, G.M. (2017). Sociality in lizards. — In: Comparative social evolution (Rubenstein, D.R. \& Abbot, P., eds). Cambridge University Press, Cambridge, p. 390-426.

Wilkinson, A. \& Huber, L. (2012). Cold-blooded cognition: reptilian cognitive abilities. - In: The Oxford handbook of comparative evolutionary psychology (Vonk, J. \& Shackelford, T.K., eds). Oxford University Press, Oxford, p. 129-141. 